\title{
EMQAL: ERASMUS MUNDUS MASTER IN QUALITY IN ANALYTICAL LABORATORIES
}

\author{
MIQUEL ESTEBAN* AND ÀNGELS SAHUQUILLO+
}

\author{
Departament de Química Analítica, Facultat de Química, Universitat de Barcelona (UB), Martí i Franquès 1-11, 08028 \\ Barcelona, Catalonia, Spain. \\ This manuscript is dedicated to the memory of Prof. Ramon Companyó (1951-2014). His efforts, enthusiasm and humanity have been \\ crucial for EMQAL project.
}

\begin{abstract}
The Erasmus Mundus Master in Quality in Analytical Laboratories (EMQAL) is a two-year Joint Master Degree. The course is funded by the European Commission through the Erasmus Mundus Programme, providing a number of attractive scholarships for European and non-European students. EMQAL prepares professionals for analytical laboratories, focusing on laboratory management and quality systems, along with complementing their technical knowledge. The EMQAL aims at training students in the most relevant issues concerning quality systems and management in analytical laboratories, and to become an expert in: Quality management, Analytical methods and Data Analysis. EMQAL promotes mobility. The students will attend one academic year of lectures in one of the European universities of the EMQAL consortium, and a 12 months master thesis at other European university, with the possibility to spend three-months in one of the non-EU partners. The language of instruction and examination is English. Further information is available at www.emqal.org.
\end{abstract}

\section{INTRODUCTION}

The Erasmus Mundus Programme (EMP), which is at present integrated inside the Erasmus+ Programme 2014-2020, was created by EU in 2004 to promote the cooperation between EU and non-EU higher education institutions (HEI) and the mobility of students. Main objective is the mobility of the most brilliant non-EU students towards European HEI. EMP represents the enhancement of the Erasmus Programme beyond Europe. The Erasmus Programme was created in 1987, and it is still active. It has been a huge academic and sociologic success in Europe. The name of the Programme is in honour of Desiderius Erasmus Roterodamus (1466 - 1536), known as Erasmus of Rotterdam, or simply Erasmus. He was a Dutch Renaissance humanist, Catholic priest, social critic, teacher, and theologian. Erasmus performed his academic career, as student and professor, in many universities around Europe. The chief centres of Erasmus's activity were Paris, Leuven, England, and Basel. He was selected as an example of intellectual activity beyond borders.

EMP supports Erasmus Mundus Master Courses (EMMCs) that are selected by means of a very exhaustive selection process. EMQAL was chosen inside EMP by the first time at 2007 Application Call and reselected at 2012 for five more editions. The $7^{\text {th }}$ EMQAL edition has started in the academic year 2014-2015.

\section{Aims of EMQAL}

EMQAL prepares professionals and scientists for analytical laboratories, focusing on laboratory management and quality systems, along with complementing their scientific and technical knowledge.

Analytical laboratories play a critical role in all aspects of modern society: in public health, in medicine, in the environment and even in trade analytical laboratories are called to provide information that makes the basis for decisions. There is a growing need to assure the quality and reliability of analytical laboratories in all countries of the world.

EMQAL project was born as an initiative of the University of Algarve, and in particular of Prof. Isabel Cavaco. EMQAL has been the pioneer project in European Higher Education for Quality in Analytical Laboratories.

\section{Main figures in EMQAL}

EMQAL is offered by a Consortium constituted by a number of partners, five European and three non-European Universities (Table 1), and ca. 20 associated partners (Table 2) including private companies, official laboratories, research institutes, national bodies and associations, as well as non-European universities in Brazil, Chile and India.

The program duration is 2 years (120 ECTS, European Credits) consisting of a 1 year taught course (60 ECTS) and 1 year of research project and thesis (60 ECTS)

First academic year (60 ECTS)

The taught course is made of stand-alone modules of 2 ECTS, which corresponds to $\mathrm{ca}$. 50 hours of workload by a standard student. A typical module of theoretical classes corresponds to 10 hours of lecturer's classes. In some cases, if some practical work is included in the module, the studentlecturer contact time (classes) can be enlarged to $c a .15$ hours. The classes are concentrated in $4-5$ days, because of the mobility of the lecturer from his/ her own university to the host one. The rest of student's time, until the named 50 hours, is required for study, preparation of exam, assignments to pass the module, etc.

During a week the student can attend one or two modules, maximum. After one month of finishing the classes, the student must provide the assignments or the exam, depending on the characteristics of the module.

The modules are distributed into three blocks of modules concerning: $i$ ) quality management (QM), ii) analytical methods (AM), and iii) data analysis (DA). Among the 30 modules (60 ECTS) selected by the student, at least 5 of each block must be chosen. Out of this, the student has the freedom to select the modules according to his/her field of interest.

Students are allowed to build their study plan according to their own interests and needs. Classes take place in one of the European Universities of the consortium and are lectured by lecturers from all the partner institutions and specialists from public agencies, private companies, etc. The Host University rotates every year (Table 3 ).

Table 4 shows an example of the list of modules offered to the students. This list can suffer some slight changes year to year, but most of the modules are offered every year.

The first academic year starts at $1^{\text {st }}$ October and, during the first 2-3 weeks of October, an intensive language course of the country of the host institution is offered as well as some cultural activities.

Upon successful completion of the program, graduates will have attained the general competencies and learning outcomes summarized in Table 5.

Second academic year (60 ECTS)

In the second year each student moves to an EU-university of the Consortium located in a different country to complete a research master thesis project (1 year) or two EU-universities (6 months each), but for an unique research and thesis project. Part of the research project (a maximum of 3 months) can be done in one of the non-European institutions of the Consortium in Brazil, Chile, China or Russia. Research projects are proposed each year by the partner institutions in the fields of laboratory accreditation, quality management, analytical methods and data analysis. These theses are integrated in on-going research projects in the Universities of the Consortium and may be offered in collaboration with public agencies and private companies (Associated Partners)

As an example, Table 6 summarizes the research master thesis projects selected by students of 2013-15 EMQAL edition.

At the end of the two-years EMMC, students will be awarded a joint diploma with a joint diploma supplement, when national (changing) regulations allow it. 


\section{EM scholarships for EMQAL students}

EMQAL is funded by the European Commission through the Erasmus Mundus Programme (EMP). As a consequence, EMP provides a number of attractive scholarships for European and non-European students. Characteristics of these scholarships are summarized in Table 7. The number of studentships is fixed by the Education, Audiovisual and Culture Executive Agency (EACEA) at Brussels and changes year to year.

The Selection criteria for these studentships follow the general rules of EMP. All eligible candidates to EMQAL are evaluated and ranked according to the following criteria:

A. Academic Excellence: Quality of previous qualifications - evaluates the academic curriculum of the candidate: previous degrees, post-graduate courses, specialization courses, scientific publications.

B. Proficiency in languages of the consortium, particularly English.

C. Motivation and Potential - measures the benefit to the candidate from the Master.

D. Suitability - match between the candidate's profile and the Master. Appropriate professional experience is evaluated.

E. Recommendations - based on the confidential evaluation of the candidate by two referees.

Each criterion A-E is scored $0-5$. Only very high quality candidates, with all criteria above 3.5 , are accepted to the course. The scores for all criteria are summed, and candidates are ranked by order of merit according to their global score (17.5-25.0)

This evaluation is made by a Selection Committee composed by representatives from each of the EU-partner universities in EMQAL. The results are published in the website as a pre-selection list of candidates to EMQAL. The pre-selection is sent to the EACEA, who will give the final approval of the candidates selected for Erasmus Mundus studentships.

Eligible candidates (not awarded by one of the restricted number of EM scholarships) can obtain an Admission Letter to EMQAL in order to apply for national or private grants programmes.

\section{EM scholarships for EMQAL scholar}

The EMP provides funds to all EMMC consortia for scholars/guest lecturers and engages those holding an outstanding academic and/or professional profile. The involvement of scholars should bring added value to the EMMC intake in terms of student-centred teaching/lecturing, research activities, Master thesis support, academic/professional networking, etc. The performed tasks and results from scholar engagements within the EMMC must be described in the context of the mandatory project reporting.

Each EMMC is expected to engage minimum 4 different scholars/guest lecturers for a minimum of 8 weeks in total. (NOTE: A "week" is defined as minimum 4 out of 7 consecutive calendar days and it is not possible to consider 8 consecutive days as 2 weeks). There is no maximum number of EMMC scholars to be engaged. The minimum duration per engagement of an EMMC scholar is 4 to 7 consecutive calendar days (= one week).

Scholars' mobility is considered eligible between the partners of the consortium (including to/from associated partners) and from an organization outside the consortium, provided it is clearly linked to the EMMC course. No scholar paid by other EU funds can be considered as eligible nor reported as EMMC scholar week.

The remuneration of scholars/guest lecturers from the management lump sum contribution can be fixed by the consortium. The amount to be paid to scholars should cover both travel/installation contribution and working fees.

\section{Final remarks}

EMQAL is an excellent Master Course as proved by the selection as EMMC at 2007 and renovation at 2012. At the moment, five editions have been completed, and two editions are running, including a total of about $120 \mathrm{EMQAL}$ students of different background such as chemists, pharmacists, chemical engineers, agricultural and environmental scientist, biologist, biochemist, microbiologists, food scientist and veterinary doctors, among others, from all over the world. In each edition, from 60-75 modules have been taught covering the three blocks (QM, AM and DA), involving up to 45 mobilities of lecturers to the Host University. More than 35 projects are offered to the students for their research master thesis yearly, including joint projects between partners, associated partners and non-European partners. In this way, EMQAL is also helping in the promotion of new collaborations between institutions with similar research interests. In each edition, some Scholars are also sharing their field of expertise not only with students but also during their research stages.

EMQAL and three other EMMCs were selected by the Action 3 Erasmus Mundus Project JOQAR as models of EMMCs in order to stablish a common procedure, at European level, for validation of master courses instead of the present national procedures. The final report of JOQAR commission pointed out the very high standards of EMQAL.

Table 1: List of EMQAL Partners.

University of Barcelona (Spain) - Coordinator

University of Algarve (Portugal)

University of Bergen (Norway)

University of Cádiz (Spain)

Gdansk University of Technology (Poland)

Central South University (China)

Novosibirsk National Research State University (Russian Federation)

University of São Paulo (Brazil)

Table 2: List of EMQAL Associated Partners.

\section{EU University or higher education institution}

Centro de Química Estructural (CQE), Portugal

Bergen University College, Norway

Non-EU universities:

Universidade Federal do Rio Grande do Norte (UFRN), Natal, Brazil

Universidade Estadual de São Paulo "Julio de Mesquita Filho"(UNESP),

Sorocaba, Brazil

Tamil Nadu Agricultural University (TNU), India

Universidad Católica del Norte (UCN), Antofagasta, Chile

\section{Public research centres (not $\mathrm{HE}$ )}

Institut de Recerca Hospital del Mar (IMIM), Spain

Institut Català de Recerca de l'Aigua (ICRA), Spain

Centre de Diagnòstic Biomèdic (CDB), Hospital Clínic de Barcelona, Spain

Enterprise large (Public)

Laboratório Central da Empresa Portuguesa das Águas Livres, SA (EPAL),

Portugal

Enterprise large (Private)

Sociedad General de Aguas de Barcelona (AGBAR), Spain

Private research centres

Water Technology Center Cetaqua (CETAQUA), Spain

Public authority (national)

Entidad Nacional de Acreditación (ENAC), Spain

Norwegian Accreditation (NAA), Norway

Public authority (regional)

Agència de Salut Pública de Barcelona (ASPB), Spain

Agencia de Gestión Agraria y Pesquera de Andalucía (AGAPA), Spain

Agència Catalana de Seguretat Alimentària (ACSA), Spain

Laboratorio Provincial de Salud Pública de Cádiz (LPSPC), Spain

Public HE research centres

Institute of Marine Research (IMR), Norway

National Institute of Nutrition and Seafood Research (NIFES), Norway

NofimaBiolab (NOFIMA), Norway

Norwegian Institute for Air Research (NILU), Norway

Non-profit / Non-governmental organization Professional associations:

Sociedad Española de Química Analítica (SEQA), Spain

Sociedade Portuguesa de Química (SPQ), Portugal

Table 3: Host universities for the first academic year.

2008-2009: University of Algarve

2009-2010: Gdansk University of Technology.

2010-2011: University of Barcelona

2011-2012: University of Algarve

2012-2013: University of Cádiz

2013-2014: University of Barcelona

2014-2015: University of Bergen

2015-2016: Gdansk University of Technology 
Table 4: Modules proposed in the 2013-14 academic year at UB (6th EMQAL Edition).

Quality Management (QM) - 23 modules

QM01 - Quality Management

QM0101 European Quality Policy and Infrastructures

QM0102 Introduction to Quality Management

QM0104 Laboratory Quality Systems: ISO/IEC 17025

QM0105 HACCP and ISO 22000

QM0106 Good Laboratory Practice

QM0107 Laboratory Quality Systems: ISO 15189

QM02 - Management

QM0202 Human Resources

QM0203 Managing Instalations, Equipment and Consumables

QM0204 Quality Systems Documentation

QM0207 Laboratory Information Management Systems (LIMS)

QM0208 Risk assessment

OM03 - Traceability

QM0302 Calibration and Verification

QM0306 Proficiency Testing Schemes and Certified Reference Materials

QM05 - Methods of analysis

QM0502 Method validation

QM0503 Technical Writing

QM0504 Internal Quality Control

QM06 - Audits

QM0601 Laboratory Audits (EN ISO 19011)

QM07 - Safety

QM0701 Chemical Safety and REACH regulations

OM08 - Postgraduate skills

QM0802 IT Tools

QM0803 Laboratory Skills

QM0804 Fieldwork Skills: practical implementation of quality management Systems

QM0805 Research Skills

QM0811 Language course - Intensive Spanish course

Data Analysis (DA) - 13 modules

\section{DA01 - Basic Statistics}

DA0101 Measuring variability and Error Propagation

DA0103 Regression Analysis

DA0104 Statistical Decision and Analysis of Variance

DA02 - Uncertainty measurement

DA0201 Introduction to Uncertainty Measurement

DA0203 Uncertainty Measurement in Chemical Tests

DA0204 Uncertainty Estimation in Clinical Analysis

DA03 - Chemometrics

DA0301 Experimental Design and Optimization

DA0302 Pattern Recognition and Classification

DA0306 Fundamentals of Multivariate data analysis

DA0307 Latent Variable Regression Techniques

DA0312 Process Analysis: modeling and non-linear parameter fitting

DA0313 Multivariate Analysis of Metabonomic and Proteomic Spectral Profiles

DA0314 Curve Resolution

Analytical Methods (AM) - 34 modules

\section{AM01 - Natural Water Analysis}

AM0101 Water Directive and CEN Standards

AM0102 Water - Sampling and general characterization

AM0104 Water - Metal Analysis

AM0105 Water - Analysis of Organic Components

AM0106 Water - Microbiological Analysis

AM02 - Food Analysis

AM0205 Foods - Sample treatment

AM0206 Functional Foods Analysis

AM0204 Foods - Microbiological analysis

AM0210 Determination of toxic substances migration from the packaging to food

AM03 - Clinical Analysis

AM0301 in Vitro Directive and CEN Standards

AM0307 Medical Microbiology
AM0309 Fundamentals of Biochemical Analysis

AM0314 Chemical fingerprinting and quality control of herbal medicines

AM05 - Environmental Analysis

AM0501 Trace Metal Water Speciation

AM0502 Atmospheric Analysis

AM0503 Soil and Sediment Analysis

AM0507 Environmental samples monitoring

AM07 - Biochemical Analysis

AM0701 Immunoassays

AM08 - Sampling

AM0801 Design of Sample Strategies and sampling techniques

AM09 - Advanced Techniques of Analysis

AM0907 Molecular Spectroscopy

AM0908 Vibrational Spectroscopy

AM0909 Quantitative IR Spectroscopy

AM0910 Atomic Spectroscopy

AM0912 Mass spectrometry

AM0913 Hyphenated techniques

AM0914 Introduction to the Electroanalytical techniques

AM0918 Automated methods of analysis

AM0919 Gas Chromatography

AM0920 Liquid Chromatography

AM0923 Extraction Methods in Analytical Chemistry

AM0925 Quality Parameters and Optimization in Chromatography

AM0926 Application of Nanomaterials in the Analytical Laboratory

AM0927 The practice of Capillary Electrophoresis: optimization and method development

AM0928 Green Analytical Chemistry

Table 5: Learning Outcomes.

1. Design, implement and manage a Quality System in any given testing or calibration analytical laboratory;

2. Develop and evaluate a quality control scheme for any given type of measurement;

3. Fully understand, both at theoretical and practical level, a set of advanced analytical techniques;

4. Research, develop and validate new techniques and methods of analysis;

5. Plan a validation program for a given method of analysis;

6. Identify critical aspects in a given method of analysis

7. Estimate the uncertainty for a given analytical result;

8. Develop Reference Materials;

9. Organize and evaluate Collaborative Studies;

10. Fully understand the current state of worldwide standardization and comparability of analytical results.

Note: These competencies can be attained in different environments, for example in the context of a clinical laboratory, or a laboratory for drinking water quality control. Students can obtain these competencies by taking 30 modules, chosen from a large set of modules that are offered in the master.

Table 6: Research master thesis projects in course (2014-2015).

- GC/MS validation method for analysis of Chlorinated hydrocarbons in underground water (UAlg).

- DRIFT and DR-UV/vis spectroscopy methods for studying the interaction of vanadium compounds with cellulose (UAlg).

- Metal Complexes as therapeutic drugs (UAlg / CQE).

- Analysis of organic contaminants in water intended for human consumption - analysis by GC-TOFMS with different sample preparation techniques (LLE, SPE and SPME) (UAlg / EPAL).

- Pharmacogenetics analysis of drug metabolizing enzymes as risk factors for breast cancer (UAlg)

- Pharmacogenetics analysis of drug metabolizing enzymes as risk factors for colorectal cancer (UAlg).

- Interlaboratory comparisons in the analysis of new reference materials (UAlg /GUT).

- Raman spectroscopy studies of polychorinated biphenyls (PCBs) effects on phospholipid liposomes (UiB / Inst. Marine Research).

- Development of extraction methods for the analysis of chemical composition from the different parts of citrus fruits (UiB / UCA).

- Analytical study of the compounds from different woods employed in the ageing of wines (UiB / UCA).

- An investigation of the chemistry involved in adding water to whisky (UiB 
/ BCE).

- Impact of omega 3 and omega 6 polyunsaturated fatty acids on the production of cyclo- and lipo- oxygenase mediated metabolites in fish cell culture experiments (NIFES / UiB).

- Comparison of new methods for determination of phenolics in vegetables (GUT / UCA).

- New analytical methods for bioactive components in foods (GUT / UCA).

- Food additives analysis (GUT/USP (Brasil). BCE: Bergen University College. Faculty of Engineering (Norway); CQE: Centro de Química Estrutural (Portugal); CSU: Central South University (China); EPAL: Empresa Pública de Águas Livres de Lisboa (Portugal); GUT: Gdansk University of Technology (Poland); IMR: Institute for Marine Research (Norway); NIFES: National Institute of Nutrition and Seafood Research (Norway); UAlg: University of Algarve (Portugal); UiB: University of Bergen (Norway); UCA: University of Cadiz (Spain); USP: Universidade de Sao Paulo (Brasil)
Table 7: Details on the EM studentships.

Payment of the participation costs for the whole EMQAL programme (including the tuition fees and the full insurance coverage)

Contribution to subsistence costs $(1000 € /$ month for the entire duration of the EMQAL study programme; 24 months).

Contribution to subsistence costs will not be given to the scholarship holders for the JMD (study /research /placement / thesis preparation) periods spent in their country of residence.

\section{Contribution to the travel and installation costs:}

$1.000 €$ per year per scholarship holder resident of a Programme Country (see NOTES) for travel costs.

$2.000 €$ per year for travel costs $+1.000 €$ for installation costs for scholarship holder resident of a Partner Country (see NOTES) whose location is situated at less than $4.000 \mathrm{~km}$ from the JMD coordinating HEI (University of Barcelona).

$3.000 €$ per year for travel costs $+1.000 €$ for installation costs for scholarship holder resident of a Partner Country whose location is situated at $4.000 \mathrm{~km}$ or more from the JMD coordinating HEI (University of Barcelona).

\section{NOTES:}

\section{PROGRAMME COUNTRIES}

Member States of the European Union (EU)

Non EU Programme Countries: former Yugoslav Republic of Macedonia, Iceland, Liechtenstein, Norway, Switzerland, Turkey

PARTNER COUNTRIES

The rest of countries (for more information consult Part B of the Erasmus + Programme Guide). 